(2) Open Access Full Text Article

\title{
Anatomy of the Pain Centre waiting list at the Centre hospitalier de l'Université de Montréal (CHUM)
}

This article was published in the following Dove Press journal: Journal of Pain Research

5 July 2013

Number of times this article has been viewed

Grisell Vargas-Schaffer ${ }^{1,2}$

Ann Rusnov ${ }^{2}$

Aline Boulanger ${ }^{1-3}$

'Pain Clinic Hôtel-Dieu, Centre Hospitalier de l'Université de Montreal CHUM, ${ }^{2}$ Centre de Recherche du Centre Hospitalier de I'Université de Montreal CRCHUM, ${ }^{3}$ Pain Clinic, Hôpital Sacre-Coeur, Montréal, Québec, Canada
Correspondence: Grisell VargasSchaffer 3840 rue Saint Urbain, Clinique antidouleur Hôtel-Dieu du CHUM, Montreal, Quebec H2WIT8, Canada $\mathrm{Tel}+|5| 48908000$

Fax +15144127132

Email grisell.vargas.chum@ssss.gouv.qc.ca
Background: Waiting list management at chronic pain clinics has become a serious problem throughout Canada. We analyzed the waiting list at the Centre hospitalier de l'Universite de Montréal (CHUM) Pain Centre.

Methods: The present study is an observational, prospective study. We used a specifically designed survey questionnaire. Survey findings were analyzed with descriptive statistical methods.

Results: A total of 270 patients were contacted; only 146 were included. Of these, 93 were women and 53 men. The average age was 55.9 years. Fifty-two percent of the patients were referred by a medical specialist; $34 \%$ by family physicians; $3 \%$ for emergency; and $11 \%$ unknown. The mean for pain score was $6.7 / 10$. Seventy-three percent were taking pain killers with an average improvement on their pain score of $52 \%$. Ten percent of respondents were not taking any type of analgesic medication, while $17 \%$ were taking over-the-counter drugs. Fiftythree percent of the patients had been suffering from chronic pain for 5 years or less, while $10 \%$ had been suffering and awaiting specialized pain treatment for more than 20 years.

Conclusion: Our data suggests that accessibility to specialized health care is not the sole obstacle to the timely and effective management of chronic pain. Seventy-three percent of the patients were taking some form of pharmaceutical treatment for pain and reported an average improvement rate of $52 \%$ on their pain score under medication. Such inconsistency may be attributable to patients' lack of compliance with their treatment. The World Health Organization Working Group recommended in chronic patients a novel approach to health care, based on patient therapeutic education. Our results show that patients need to acquire self-management skills regarding their chronic conditions.

Keywords: chronic pain clinics, waiting list management, patient referral, waiting list demographics

\section{Introduction}

In today's society, chronic pain is justly regarded as a disease and a social health care problem. In Canada, 3.9 million people aged 15 years and over suffer from chronic pain, $70 \%$ (2.8 million) at severe pain levels with disabling effects on their daily activities. ${ }^{1}$ Chronic pain represents a serious functional impairment and a social predicament with debilitating repercussions on sufferers' personal, familial, and socioeconomic life. ${ }^{1-7}$ Accordingly, there is a critical need to address the growing prevalence of chronic pain and to devise workable solutions for timely access to multidisciplinary health care services like those provided at the Centre hospitalier de l'Université de Montréal (CHUM) Hôtel-Dieu Pain Centre. 
The majority of studies conducted on the quality of and access to health care treatments have historically focused on the length of wait times for surgery and diagnostic procedures. ${ }^{8-16}$ To our knowledge, the only study to address the issue of waiting list management in a specialized pain treatment center was conducted in Halifax in 2005 by Clark et al. ${ }^{17}$

The objectives of the present study were as follows: to analyze the waiting list at the CHUM Pain Centre; to identify the primary motives for patient referrals; to delineate the demographic characteristics of wait-listed patients; and to identify the nature of diagnostic procedures leading to patient referral.

\section{Methods}

This observational, prospective study was conducted over a 6-month period during 2008; it involved the screening of 146 patients referred to and awaiting treatment at the CHUM Hôtel-Dieu Pain Centre in conjunction with a chronic-pain diagnosis. The study was approved by the Ethical Committee of Hôtel-Dieu du CHUM.

Our examination of waiting list data proceeded along the following pathways:

- In-depth scrutiny of the list in order to:

o Eliminate duplicate referrals;

o Delineate patient groups according to type of request for consultation:

1. Requests for invasive treatments (epidurals, nerve blocks, infiltrations, etc).

2. Requests for management of pain medication.

3. Requests for a multidisciplinary intervention.

o Delineate patient groups according to type of pain.

- Development of a survey questionnaire providing an overview of wait-listed patients.

The survey questionnaire, developed by a CHUM Pain Centre practitioner, was specifically designed to ascertain the profile of wait-listed patients and the nature of their pain. The 15-minute questionnaire, administered by a Pain Centre research nurse, enabled us to compile and analyze the following data: patient demographic characteristics and consultation history; origin of pain; current situation with regard to pain management; impact of pain on patient's quality of life; and patient expectations of the Pain Centre.

Analytical findings were grouped under three sets of data:

- Demographic data: age and gender distribution; referring institution/service; access to a family physician; and referral diagnosis.
- Pain history data: interval between pain onset and request for consultation at the Pain Centre; rating of pain intensity levels (overall, at rest, during activities, and during sleep) measured on a simple 1 to 10 numeric scale; and origin of pain.

- Pain management data: diagnostic procedures prior to referral; analgesic treatments past and present; assessment of prescribed pain treatment efficacy (ie, percentage of improvement on pain score); and resort to alternative treatment approaches.

Expectations of the CHUM Pain Centre were evaluated on the basis of patients' responses to the following questions: "What are your expectations of the Pain Centre? Do you believe your level of pain can be reduced and your quality of life enhanced by less than $40 \%$, by $40 \%-70 \%$ or by more than $70 \%$ ?"

Survey findings were analyzed and synthesized using a descriptive statistical method (proportions, averages, and standard deviation).

\section{Results}

Among the 270 patients contacted by phone, 124 patients were removed from the waiting list for a variety of reasons; $146(54 \%)$ responded to the survey questionnaire and were seen by a Pain Centre specialist (Figure 1).

Of the 146 respondents surveyed, 93 (64\%) were women and $53(36 \%)$ were men. The overall median age was 55.9 years, 57.0 years for women and 54.0 years for men, representing a 14.0 standard deviation. The youngest patient referred was 19 years of age and the oldest was 90 years old.

The centers referring patients to the CHUM Pain Centre were: CHUM (44.5\%), other Montreal hospitals (28.8\%), Montreal's private clinics (17.8\%), medical centers outside Montreal (7.5\%), and undetermined sources (1.4\%).

More than half of the wait-listed cohort was referred (52\%) by a medical specialist; $34 \%$ were referred by a family physician; $3 \%$ by a hospital emergency ward; and $11 \%$ by an unknown source (see Table 1). Almost all (85\%) of the patients surveyed had access to a primary care physician, indicating that only $15 \%$ did not.

Table 2 illustrates referral diagnoses, $50 \%$ of which were for spinal column pain.

An examination of wait times between pain onset and request for consultation at the CHUM Pain Centre revealed that $53 \%$ of patients had been suffering from chronic pain for 5 years or less; while $10 \%$ had been suffering and awaiting specialized pain treatment for more than 20 years (see Table 3). 


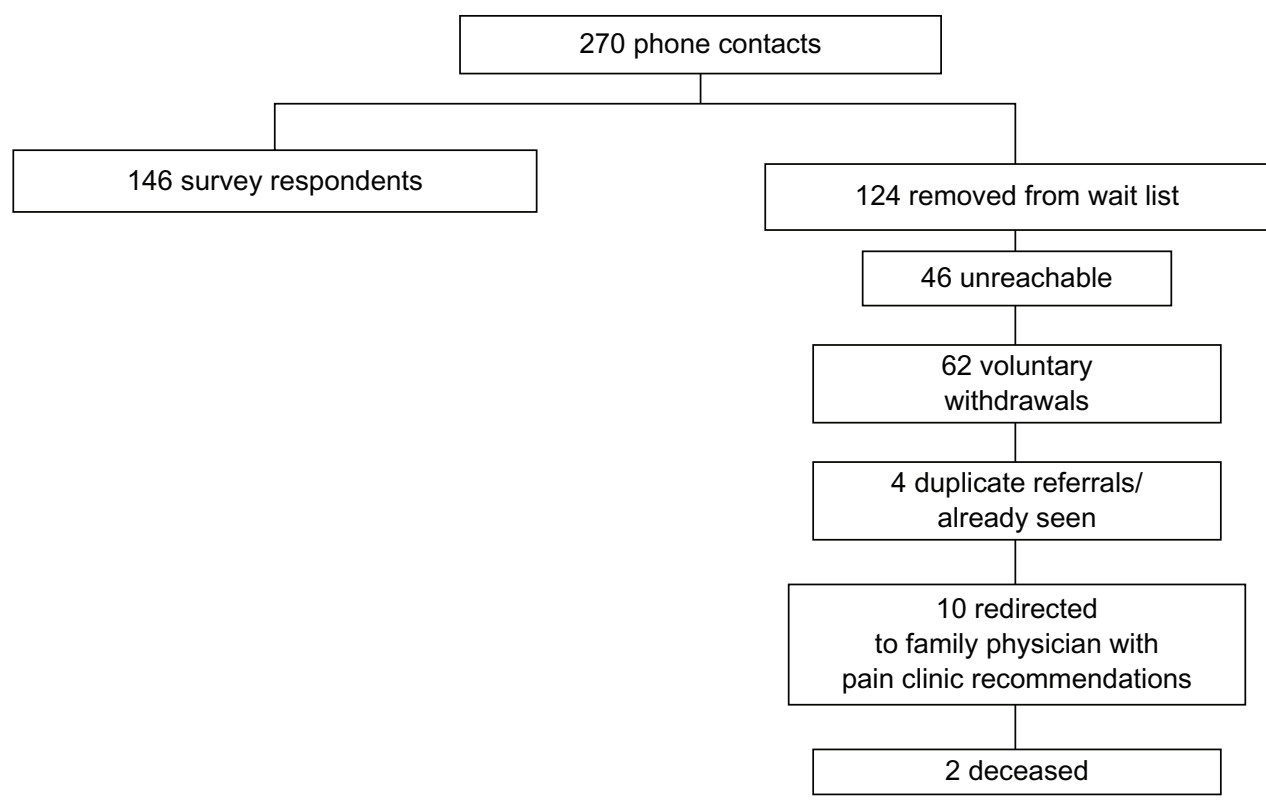

Figure I Participant flow and response rate.

Overall pain intensity levels (see Table 4) were measured on a simple 1 to 10 numeric rating scale over 24 hours, at rest, during activities, and during sleep. In 146 surveyed respondents, the mean pain intensity level reported was $6.7 / 10$. Nearly $60 \%$ of patients reported severe pain levels in the course of activities or movement, while between $35 \%$ and $42 \%$ reported decreased pain levels at rest and during sleep.

Survey respondents reported multiple origins of pain. Thirty-nine percent were believed to be spontaneous in origin; $40 \%$ were accident-related and could be broken down to (a) $12 \%$ automobile accidents, (b) $14 \%$ work-related accidents, and (c) 14\% caused by various traumatisms. Sixteen percent were related to medical interventions and $1 \%$ was

Table I Originating services - requests for consultation at the CHUM Pain Centre

\begin{tabular}{lll}
\hline Originating service & $\begin{array}{l}\text { Number } \\
\text { of patients }\end{array}$ & $\begin{array}{l}\text { Percentage } \\
\text { of patients }\end{array}$ \\
\hline $\begin{array}{l}\text { Specialized medical service } \\
\text { (endocrinology, internal medicine, }\end{array}$ & 53 & 36 \\
$\begin{array}{l}\text { microbiology, neurology, oncology, } \\
\text { physiatrists, pneumonology, psychiatry, } \\
\text { rheumatology, detoxification facility) }\end{array}$ & & \\
$\begin{array}{l}\text { General medicine } \\
\text { Surgery (anesthetics, general surgery, } \\
\text { neurosurgery, plastic surgery, }\end{array}$ & 23 & 34 \\
$\begin{array}{l}\text { orthopedic surgery) } \\
\text { Emergency }\end{array}$ & 16 \\
$\begin{array}{l}\text { Unknown } \\
\text { Total }\end{array}$ & 4 & \\
\hline
\end{tabular}

Abbreviation: CHUM, Centre hospitalier de l'Université de Montréal. related to systemic diseases. Unavailable data accounted for $4 \%$ of respondents.

Psychological implications at the time of survey: 19\% of patients $(n=28)$ had been seeing a psychologist in connection with their chronic pain.

Figure 2 illustrates patients' employment status: 77\% $(\mathrm{n}=112)$ were unemployed, while $22 \%(\mathrm{n}=32)$ held a job (of which $9 \%$ was part-time and $13 \%$ was full-time employment). Hence, $59 \%$ of those working were employed full time, against $40 \%$ who were part-time employees. Two patients declined to answer the question on employment.

Table 2 CHUM Pain Centre - referral diagnoses

\begin{tabular}{lll}
\hline Referral diagnosis & $\begin{array}{l}\text { Number } \\
\text { of patients }\end{array}$ & $\begin{array}{l}\text { Percentage } \\
\text { of patients }\end{array}$ \\
\hline Arthritis/osteoarthritis & 3 & 2 \\
Abdominal pain & 2 & 1.4 \\
Chronic pain & 16 & 11 \\
Ischemic pain & 1 & 0.7 \\
Musculoskeletal pain & 4 & 2.7 \\
Postoperative pain & 3 & 2 \\
Thoracic pain & 2 & 1.4 \\
CRPS & 13 & 8.9 \\
Fibromyalgia & 18 & 12.3 \\
Neuropathic pain and & 11 & 7.5 \\
postherpetic neuralgia & & \\
Rachidian pain (lumbar, sciatica & 73 & 50 \\
neuralgia, dorsal, cervical, spinal & & \\
stenosis, failed back pain) & & 100 \\
Total & I46 & \\
\hline Abbreviations: CHUM, Centra hospitalier de l'Université de Montréal: CRPS
\end{tabular}

Abbreviations: CHUM, Centre hospitalier de l'Université de Montréal; CRPS, complex regional pain syndrome. 
Table 3 Wait-listed patients - number of years in pain

\begin{tabular}{llll}
\hline $\begin{array}{l}\text { Number of years } \\
\text { in pain }\end{array}$ & $\begin{array}{l}\text { Number } \\
\text { of patients }\end{array}$ & $\begin{array}{l}\text { Percentage } \\
\text { of patients }\end{array}$ & $\begin{array}{l}\text { Standard } \\
\text { deviation }\end{array}$ \\
\hline 0-5 years & 77 & 53 & 3.60 \\
$6-10$ years & 36 & 24 & 2.68 \\
II-20 years & 13 & 9 & 0.69 \\
$>20$ years & 16 & 11 & 0.65 \\
Unavailable & 4 & 3 & \\
\hline
\end{tabular}

Financial implications: $23 \%(n=33)$ of survey respondents were receiving a financial compensation (disability insurance), while $54 \%(\mathrm{n}=79)$ reported other sources of revenue or no revenue.

Diagnostic exams performed prior to patient referral to the Pain Centre included: X-ray, ultrasound, computed tomography (CT) scan, electromyography, magnetic resonance imaging (MRI), bone scan, Doppler, myelography, and mammography. Ninety-seven percent of survey respondents had undergone at least one diagnostic procedure prior to being referred to the Pain Centre; only five of the 146 had undergone none. Fifty-six patients (38\%) had undergone more than one diagnostic exam (eg, X-ray and MRI). Of the 177 tests performed, $38 \%(n=67)$ were MRIs, $22 \%(n=38)$ were X-rays and $19 \%(n=34)$ were CT scans.

Of the 146 patients surveyed, $73 \%$ were taking some form of pharmaceutical treatment for pain prescribed by a referring specialist or general practitioner (see Table 5). These patients reported an average improvement rate of $52 \%$ on their pain score under medication. Ten percent of respondents were not taking any type of analgesic medication, while $17 \%$ were taking over-the-counter drugs.

Research data on previous pharmaceutical treatments and reasons for discontinuation were: side effects, ineffectiveness, and fear of addiction to opioids. It is worth noting that 42 respondents were unable to recall the names of medication taken previously, although they could ascertain having experimented with a variety of pain medication. In fact, only 16 patients $(11 \%)$ indicated never having tried any form of pain medication other than what they were taking at the time of survey.

Table 4 Pain intensity levels

\begin{tabular}{llll}
\hline Pain intensity level & $\mathbf{0 - 4}$ & $\mathbf{5 - 7}$ & $\mathbf{8 - 1 0}$ \\
\hline Overall pain intensity over 24 hours & 6.8 & 54.1 & 29.4 \\
Pain intensity at rest & 35.6 & 31.5 & 21.9 \\
Pain intensity during activities & 0.7 & 30.8 & 58.9 \\
Nocturnal pain intensity & 42.5 & 25.3 & 21.9 \\
\hline
\end{tabular}

Note: Pain intensity was measured on a scale of $\mathrm{I}$ to 10.

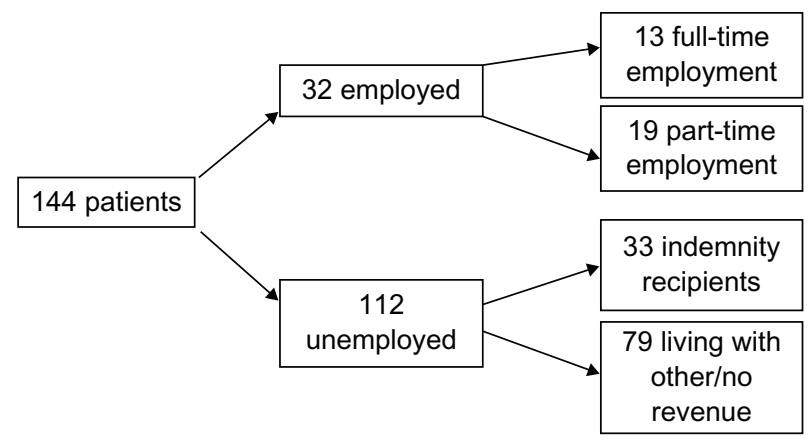

Figure 2 Patients' employment status.

Seventy-six percent of patients admitted to seeking relief through alternative modes of treatment such as: physiotherapy $(46 \%)$, acupuncture (15\%), osteopathy $(12 \%)$, massage therapy $(6 \%)$, chiropractic treatment $(5 \%)$, occupational therapy (5\%), and other forms of therapy (kinesiotherapy, balneotherapy/hydrotherapy) (6\%). Thirty-one percent $(n=45)$ experimented with more than one approach or combined several (eg, acupuncture and physiotherapy).

Other treatment options used by 23 patients $(16 \%)$ included natural products such as glucosamine, vitamins, minerals, and homeopathic remedies. It was noted that ten patients (7\%) said they used marijuana regularly as a means to alleviate pain.

Expectations of the CHUM Pain Centre were evaluated on the basis of patients' responses to the following questions: "What are your expectations of the CHUM Pain Centre? Do you believe your level of pain can be reduced and your quality of life enhanced by less than $40 \%$, by $40 \%-70 \%$, or by more than $70 \%$ ?" (See Table 6 for patient responses).

\section{Discussion}

The purpose of multidisciplinary pain centers is to direct patients toward interdisciplinary care units offering slightly

Table 5 Patient pharmacology at time of survey

\begin{tabular}{ll}
\hline Pain medication & $\begin{array}{l}\text { Number of patients } \\
\text { with prescription }\end{array}$ \\
\hline Acetaminophen & 27 \\
Tricyclic antidepressants & 17 \\
NSAID and COX2 & 36 \\
Cannabinoids & 1 \\
Codeine & 12 \\
Gabapentinoids & $4 \mathrm{I}$ \\
Muscle relaxants & 8 \\
Opioids (pethidine, morphine, oxycodone, & 81 \\
hydromorphone, fentanyl, methadone) & \\
Tramacet & 4 \\
Topamax & 2 \\
\hline
\end{tabular}

Abbreviation: COX2, cyclooxygenase 2 selective inhibitors; NSAID, nonsteroidal anti-inflammatory drugs. 
Table 6 Patients' expectations of the CHUM Pain Centre

\begin{tabular}{llllll}
\hline Patient expectations & $\mathbf{0 \% - 4 0 \%}$ & $\mathbf{4 0} \%-\mathbf{7 0} \%$ & $\mathbf{7 0} \%-\mathbf{1 0 0} \%$ & Don't know & Unavailable \\
\hline Pain reduction & 29 & 46 & 36 & 20 & 15 \\
Improved quality of life & 30 & 43 & 38 & 20 & 15 \\
\hline
\end{tabular}

Abbreviation: CHUM, Centre hospitalier de l'Université de Montréal.

unconventional and/or invasive treatments, the ultimate goal being to refer them back to their general practitioner for follow-up once pain is stabilized or under control. In truth, however, this is rarely the case. All too often, patients treated at the pain center do not follow this scenario because referring physicians fail to provide adequate follow-up. This is all the more surprising in light of the fact that $85 \%$ of our respondents had access to a family doctor, at a time when Quebec is experiencing critical shortages in that area. This unfortunate situation has led to the overburdening of multidisciplinary pain centers and their diminished capacity to take on new patients.

Although $73 \%$ of respondents undergoing pharmacological pain treatment cited improvement rates between $25 \%$ and $70 \%, 54 \%$ reported an average pain intensity level over 24 hours of 5 to 7 on the numerical rating scale of 10 . Such inconsistency may be attributable to patients' lack of compliance with their treatment rather than ineffectiveness of medication (eg, failure to follow instructions; taking medication on a pro re nata [PRN] basis rather than a permanent, regular basis). This could explain temporary relief obtained when taking medication and recurring elevated pain levels.

Eighty-one patients (55\%) reported taking some form of prescription opioid (pethidine, morphine, oxycodone, hydromorphone, fentanyl, or methadone). This would indicate that, contrary to reports from previous studies, ${ }^{13} \mathrm{a}$ considerable number of physicians are aware of opioids' key role in the management of chronic pain and prescribe them on a regular basis.

Wait list management at chronic pain specialty clinics has become a serious concern throughout Canada. ${ }^{14-16}$ For this reason, the Canadian Pain Society, a chapter of the International Association for the Study of Pain, commissioned a task force to carry out a systematic review of the literature. The intended goal of the task force was to establish medically appropriate wait time benchmarks for the effective treatment of chronic pain. ${ }^{18,19}$ The authors took into account a number of Canadian studies in order to better understand and identify solutions to the challenges posed by wait list management at specialized pain centers. In its conclusion, the task force contends that a medically acceptable threshold for the adequate treatment of chronic pain should not exceed 6 months.
Evidence from our survey indicates that $10 \%$ of patients had been living with chronic pain for over 20 years; this suggests that lack of access to specialized health care is not the sole obstacle to the timely and effective management of chronic pain. Clearly, the problem exists in a complex reality. The chronicity of pain is related to multiple contributing factors: lack of compliance with or poor adherence to therapeutic treatment; lack of patient empowerment through enhanced awareness and education programs; lack of health professional training in chronic pain and its treatment options; and lack of interest and training among certain primary care physicians and their failure to provide long-term follow-up to chronic pain sufferers. ${ }^{19-23}$

Detailed study of waiting lists in pain centers can provide clues and solutions. In our particular case, the screening of the list allowed us to know that $46 \%$ of patients were not interested in being wait-listed. It is our opinion that the screening process should involve a physician and a clinical nurse.

The growing prevalence of chronic pain has led to profound changes in the patient-physician relationship. A novel approach to health care, based on patient therapeutic education, has been documented in a 1998-1999 report of the World Health Organization (WHO) Working Group. ${ }^{24}$ The value of this approach was first demonstrated in the treatment of diabetic and asthmatic patients; it has since been applied in several other chronic illness situations and proven helpful in the management of behavioral risk factors such as alcohol and tobacco dependency, stress, sedentary lifestyle, dyslipidemia, hypertension, weight gain, and obesity. Regrettably, to our knowledge, no similar trials have been conducted in the area of chronic pain. It is safe to assume, however, that a similar approach could yield positive results in the latter area.

\section{Limitations}

Our study had several limitations. The population sample was too limited. Only $54 \%$ of patients contacted responded to the survey questionnaire. The information gathered concerning pain treatment was often incomplete or approximate. The implementation of an adequate reference to a specialized pain may be a clue to follow to avoid irrelevant references. 
The financial implications for chronic pain were not exhaustively studied. Patients' expectations were not clearly ascertained.

\section{Conclusion}

The problem of waiting lists in chronic pain centers is real and complex, it involves different aspects, including among others: (a) lack of knowledge of how to handle and make good management of waiting lists, (b) failure of economic resources and reduced number of health professionals to work with chronic pain patients, (c) lack of awareness of the reality of chronic pain as a disease and not just a symptom, (d) lack of patient education, and (e) patients' expectations.

Wait list management at multidisciplinary pain treatment centers is a multifaceted undertaking that cannot be reduced to an issue of numbers. Resorting to multidisciplinary treatment centers should be limited to patients showing signs of unresponsiveness to conventional treatments. An examination of our wait list data indicates that numerous patients had been suffering for a long time prior to being referred to us. Hence, the problem is understood to exist at multiple levels: failure of medical schools to provide adequate training in pain morphology and treatment; lack of continuity in primary care treatment prior to referral; and lack of therapeutic education programs to help patients lead healthier lifestyles in spite of chronic pain, to enhance compliance with treatment, and to promote the integration of appropriate exercise routines in their daily regimen. In its 1998-1999 report, the WHO Working Group set out to define the concept of "patient therapeutic education."24-38 The creation and implementation of therapeutic education programs is one of the avenues to be explored to potentially alleviate the burden of long term, chronic pain cases. Another clue can be to designate a clinical nurse/physician to periodically screen the referrals and the wait list.

In summary, a detailed study of the waiting list can help to better assess the list and will allow patients to have access to the right care at the right time.

\section{Disclosure}

The authors report no conflicts of interest in this work.

\section{References}

1. Ipsos-Reid. [Third Annual National Report on Health]. Troisième bulletin national annuel sur la santé. Ottawa: Association Médicale Canadienne. 2012. French.

2. Lazorthes Y. [Chronic pain or pain with disease]. La douleur chronique ou douleur - maladie. In: Lazorthes Y, editor. Les douleurs rebelles. Évaluation et stratégie thérapeutique. Paris: Maloine; 1993. French.
3. Serrie A. [Assessment of chronic pain]. Évaluation d'une douleur chronique. In: Serrie A, Thurel C, editors. La douleur en practique quotidienne: Diagnostic et traitements. Arnett; 1994. French.

4. Woolf CJ, Decosterd I. Implications of recent advances in the understanding of pain pathophysiology for the assessment of pain in patients. Pain. 1999;Suppl 6:S141-S147.

5. Doubell TP, Mannion RJ, Woolf CJ. The dorsal horn: state dependent sensory processing, plasticity and the generation of pain. In: Wall PD, Melzack R, editors. Textbook of Pain, 4th ed. Edinburgh: Churchill Livingstone; 1999;165-182.

6. Liebeskind JC. Pain can kill. Pain. 1991;44(1):3-4.

7. Davies HT, Crombie IK, Macrae WA. Waiting in pain. Delays between referral and consultation in outpatient Pain Centres. Anaesthesia. 1994;49(8):661-665.

8. Ipsos-Reid, Ottawa Public Affairs and Global International Services. Stakeholder Perspectives on Wait List Management in Four Countries: Draft Report. 2004.

9. [Meeting of the Association Presidents and the Minister of Health improvements to the first line] Rencontre des présidents d'association et du ministre de la Santé des améliorations pour la première ligne. XVe congrès syndical de la FMOQ - 1. Le Médecin du Québec. 2006;40(12):14-15. French.

10. Pitt DF, Noseworthy TW, Guilbert J, Williams JR. Waiting lists: management, legalities and ethics. Can J Surg. 2003;46(3):170-175.

11. Lewis S, Barer ML, Sanmartin C, Sheps S, Shortt SE, McDonald PW. Ending waiting-list mismanagement: principles and practice. CMAJ. 2000;162(9):1297-1300.

12. Western Canada Waiting List Project. "Update from Alberta." Update WCWL Newsletter; Jul 2009.

13. Connor-Spady BL, Arnett G, McGurran JJ, Noseworthy TW; The Steering Committee of the Western Canada Waiting List Project. Prioritization of patients on scheduled waiting lists: validation of a scoring system for hip and knee arthroplasty. Can J Surg. 2004;47(1):39-46.

14. McDonald P. Waiting Lists and Waiting Times for Health Care in Canada: More Management!! More Money?? Ottawa: Health Canada; 1998. Available from: http://www.hcsc.gc.ca/english/media/releases/ waiting_list.html. Accessed May 31, 2013.

15. Blendon RJ, Schoen C, DesRoches CM, Osborn R, Scoles KL, Zapert K. Inequities in health care: a five-country survey. Health Aff (Millwood). 2002;21(3):182-191.

16. Edwards N, Riley B. Can we develop wait list for public health issues? CMAJ. 2006;174(6):794-796.

17. Clark AJ, Beauprie I, Clark LB, Lynch ME. A triage approach to managing a two-year waiting list in a chronic pain program. Pain Res Manag. 2005;10(3):155-157.

18. Morley-Forster PK, Clark AJ, Speechley M, Moulin DE. Attitudes toward opioid use for chronic pain: a Canadian Physician Survey. Pain Res Manag. 2003;8(4):189-194.

19. A Canadian Pain Society Task Force Towards Establishing Evidence Based Benchmarks for Acceptable Waiting Times for Treatment of Pain. Dec 2005. Available from: http://www.hc-sc.gc.ca. Accessed June 19, 2013.

20. Mary E Lynch, Fiona Campbell, Alexander J Clark, et al. A systematic review of the effect of waiting for treatment for chronic pain. Pain. 2008;136:97-116.

21. The Canadian Pain Society. Accreditation Pain Standard: Making it Happen! Oshawa: The Canadian Pain Society; 2005. Available from: http://www.canadianpainsociety.ca/pdf/accreditation_manual.pdf. Accessed May 31, 2013.

22. Peng P, Chouinere M, Dion D, et al. Characterization of multidisciplinary pain treatment facilities (MPTF) in Canada: Stop Pain Project-Study II. Pain Res Manag. 2006;11:121.

23. The British Pain Society. Adult Chronic Pain Management Services in Primary Care. London; 2004. Available from: http://www.drfoster. co.uk/images/pain\%20report\%20final.pdf. Accessed May 31, 2013. 
24. World Health Organization. Therapeutic Patient Education. Continuing Education Programmes for Health Care Providers in the Field of Prevention of Chronic Diseases. Geneva: World Health Organization; 1998. Available from: http://www.euro.who.int/_data/assets/pdf_ file/0007/145294/E63674.pdf. Accessed May 31, 2013.

25. Turk DC, Rudy TE. Neglected topics in the treatment of chronic pain patients - relapse, noncompliance, and adherence enhancement. Pain. 1991;44(1):5-28.

26. Ready LB, Sarkis E, Turner JA. Self-reported vs actual use of medications in chronic pain patients. Pain. 1982;12(3):285-294.

27. Kabat-Zinn J, Lipworth L, Burncy R, Sellers W. Four-year follow-up of a meditation-based program for the self-regulation of chronic pain: treatment outcomes and compliance. Clin J Pain. 1986;2(3):159-774.

28. McCarberg BH, Barkin RL. Long-acting opioids for chronic pain: pharmacotherapeutic opportunities to enhance compliance, quality of life, and analgesia. Am J Ther. 2001;8(3):181-186.

29. Bodenheimer T, Lorig K, Holman H, Grumbach K. Patient selfmanagement of chronic disease in primary care. JAMA. 2002;288(19): 2469-2475.

30. Chodosh J, Morton SC, Mojica W, et al. Meta-analysis: chronic disease self-management programs for older adults. Ann Intern Med. 2005;143(6):427-438.

31. Assal JP. [Treatment of disease of long duration of the acute phase at the stage of chronicity. Another disease management, another process management]. Traitement des maladies de longue durée: de la phase aiguë au stade de chronicité. Une autre gestion de la maladie, un autre processus de prise en charge. Encycl Med Chir Thérapeutique. 1996. French.

32. Assal JP, Golay A. [The long-term monitoring of chronic patients: new dimensions of the therapeutic time]. Le suivi à long terme des patients chroniques: les nouvelles dimensions du temps thérapeutique. Med Hyg. 2001;59(2553): 1446-1450. French.
33. Ruiz J. [Therapeutic support, the path to follow long-term]. Accompagnement thérapeutique: le chemin du suivi à long terme. Rev Med Suisse. 2008;4:1405-1409. French.

34. Haute Autorité de Santé. [Methodological guide. Structuring a therapeutic patient education program in the field of chronic diseases]. Guide méthodologique. Structuration d'un programme d'éducation thérapeutique du patient dans le champ des maladies chroniques. Saint-Denis La Plaine: Haute Autorité de Santé; 2008. Available from: http://www. has-sante.fr/portail/upload/docs/application/pdf/etp_-_guide_version_ finale_2_pdf.pdf. Accessed May 31, 2013. French.

35. Grenier B, Bourdillon F, Gagnayre R. [The development of treatment education in France: current care policies]. Le développement de l'éducation thérapeutique en France: politiques publiques et offres de soins actuelles. Santé Publique. 2007;4(19):283-292. French.

36. Lecimbre E, Gagnayre R, Deccache A, d'Ivernois JF. [The role of patient associations in the development of treatment education in France]. Le rôle des associations de patients dans le développement de l'éducation thérapeutique en France. Santé Publique. 2002;4(14):389-401. French.

37. Chambouleyron M, Lasserre-Moutet A, Vanistendael S, Lagger G, Golay A. [A new program in management education: training caregivers to promote the resilience of patients]. Un nouveau programme en éducation thérapeutique: former des soignants pour favoriser la résilience des patients. Pédagogie médicale. 2007;8(4):199-206. French.

38. van Ballekom K. [Patient education in the Netherlands and Belgium. Policies and practices in training, education and accompanying the patient to the hospital]. L'éducation du patient aux Pays-Bas et en Belgique. Pratiques et politiques dans l'instruction, l'éducation et l'accompagnement du patient à l'hôpital. Ther Patient Educ. 2009;1(2): 219-227. French.
Journal of Pain Research

\section{Publish your work in this journal}

The Journal of Pain Research is an international, peer-reviewed, open access, online journal that welcomes laboratory and clinical findings in the fields of pain research and the prevention and management of pain. Original research, reviews, symposium reports, hypothesis formation and commentaries are all considered for publication.

\section{Dovepress}

The manuscript management system is completely online and includes a very quick and fair peer-review system, which is all easy to use. Visit http://www.dovepress.com/testimonials.php to read real quotes from published authors. 